\title{
Study of the Structure of Crater at the Surface of 12Cr18Ni10Ti Steel Irradiated by High-Power Pulsed Ion Beam
}

\author{
M. V. Zhidkov ${ }^{a, *}$, A. E. Ligachev ${ }^{b, * * *}$, G. V. Potemkin ${ }^{c, * * * *}$, S. S. Manokhin ${ }^{a, d}, * *$, \\ G. E. Remnev ${ }^{c, * * * * *}$, and Yu. R. Kolobov ${ }^{a, d}, * * * * * *$ \\ ${ }^{a}$ Belgorod State National Research University, Belgorod, 308015 Russia \\ ${ }^{b}$ Prokhorov Institute of General Physics, Russian Academy of Sciences, Moscow, 119991 Russia \\ ${ }^{c}$ Tomsk Polytechnic University, Tomsk, 634050 Russia \\ ${ }^{d}$ Institute of Problems of Chemical Physics, Russian Academy of Sciences, Chernogolovka, Moscow oblast, 142432 Russia \\ *e-mail: zhidkov@bsu.edu.ru \\ **e-mail:manohin@bk.ru \\ ***e-mail:carbin@yandex.ru \\ $* * * * e$-mail: ep.gvp@yandex.ru \\ *****e-mail: remnev06@mail.ru \\ ******e-mail:kolobov@bsu.edu.ru \\ Received October 5, 2017
}

\begin{abstract}
The topography of surface layers of 12Cr18Ni10Ti (AISI 321) steel after pulsed high-power $\mathrm{C}^{n+}$ ion beams irradiation was investigated by scanning electron microscopy. A thin foil was prepared from the cross section of a crater with the use of a focused ion beam in the column of a two-beam electron-ion microscope. The microstructure and chemical composition of the crater were studied by transmission electron microscopy. It is shown that the nearsurface layer ( $\sim 2 \mu \mathrm{m}$ in depth) of the crater is represented by an area of columnar grains elongated in the direction of the surface. Under the layer of columnar grains, the region with equiaxial submicrocrystalline grains is situated.
\end{abstract}

Keywords: high-power pulsed ion beams, surface, crater, structure

DOI: $10.1134 / \mathrm{S} 2075113318030322$

\section{INTRODUCTION}

The mechanism of the appearance of craters on the surface of metals after the action of high-power pulsed ion beams (HPPIB) is still a subject of debate. In this connection, one can hope that an experimental study of the regularities and structural mechanisms of the processes of crater formation will help optimize the processing regimes of HPPIB materials and formulate practical recommendations for obtaining materials and products with given surface properties and near-surface layers.

In this paper, the microstructure of a crater formed on the surface of $12 \mathrm{Cr} 18 \mathrm{Ni} 10 \mathrm{Ti}$ stainless steel after irradiation with a high-power pulsed ion beam is studied. The test surface was ground and polished to "mirror gloss" on a LaboPol-5 (Struers) installation. The irradiation was carried out at the TEMP accelerator [1] with a $250-\mathrm{keV} \mathrm{C}^{n+}$ ion beam at the pressure of residual gases in the chamber of $(4-5) \times 10^{-2} \mathrm{~Pa}$. The pulse duration was $\sim 100 \mathrm{~ns}$, and the current density in the pulse was $150-200 \mathrm{~A} / \mathrm{cm}^{2}$. The surface was subjected to ten pulses at the energy density in a pulse of $\sim 3 \mathrm{~J} / \mathrm{cm}^{2}$. The topography of the surface of the irradiated sample was studied with a Zeiss Ultraplus scan- ning electron microscope. The thin foil cut from the cross section of the crater, obtained by ionic thinning of the crater material with a focused ion beam on a FEI Helios 660 scanning electron microscope, was examined on a Tecnai G2 20F S-T (FEI) transmission electron microscope.

For craters formed on the surface, whose density was not less than $1 \times 10^{4} \mathrm{~cm}^{-2}$, central symmetry and the presence of a ring structure are characteristic. There are craters both with a pronounced ring structure and with weak and diffuse peripheral rings, while in the center of the crater there may be either a cavity or a peak. All this creates a visible variety of shapes and sizes of surface defects (Fig. 1a).

To study the internal structure of the crater, an annular single crater of $\sim 40 \mu \mathrm{m}$ in size with a cavity in the center was selected (Fig. 1b). As a result of successive ion thinning, a thin $(\sim 90 \mathrm{~nm})$ foil of the cross section of the crater with an area of interest of $10^{3} \mu \mathrm{m}$ was obtained (inset in Fig. 1b).

Figure 2 shows the structure of the cross section of the crater. According to the data of transmission scanning electron microscopy, the surface layer of the cra- 

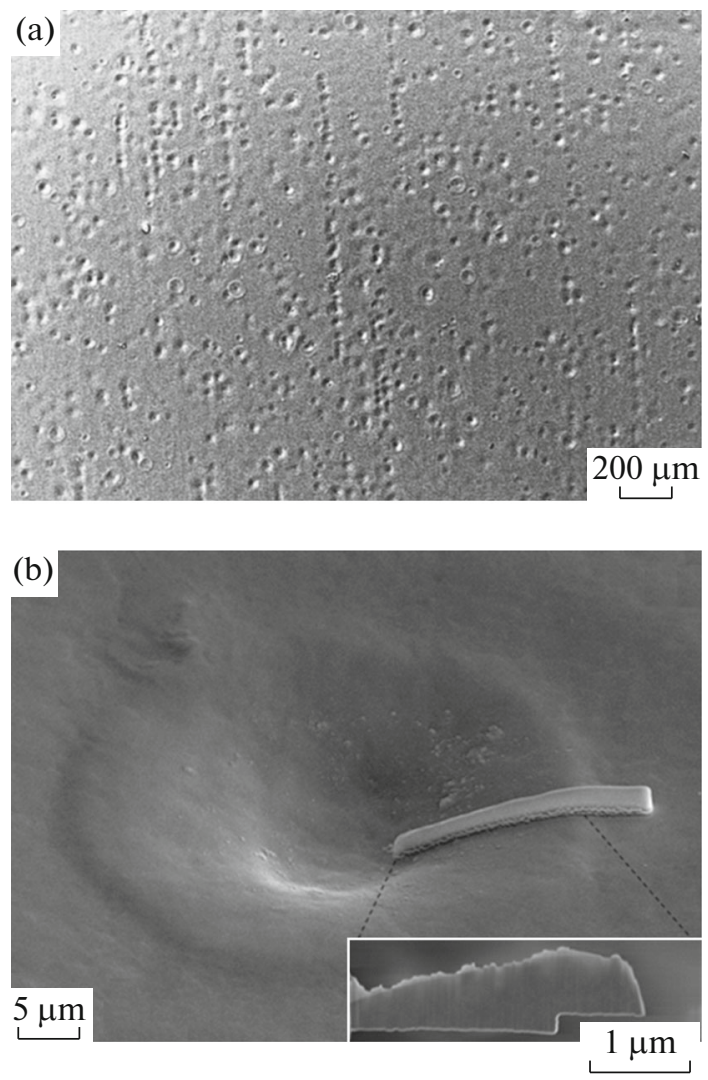

Fig. 1. Topography of the surface of $12 \mathrm{Cr} 18 \mathrm{Ni} 10 \mathrm{Ti}$ steel after the action of ten pulses of high-power pulsed ion beam at energy density of $3 \mathrm{~J} / \mathrm{cm}^{2}$ (a) and crater coated with Pt protective layer (b). Tilt angle of specimen in the microscope column is $52^{\circ}$. Image of the foil $\sim 90 \mathrm{~nm}$ in thickness extracted from the specimen is presented in the inset.

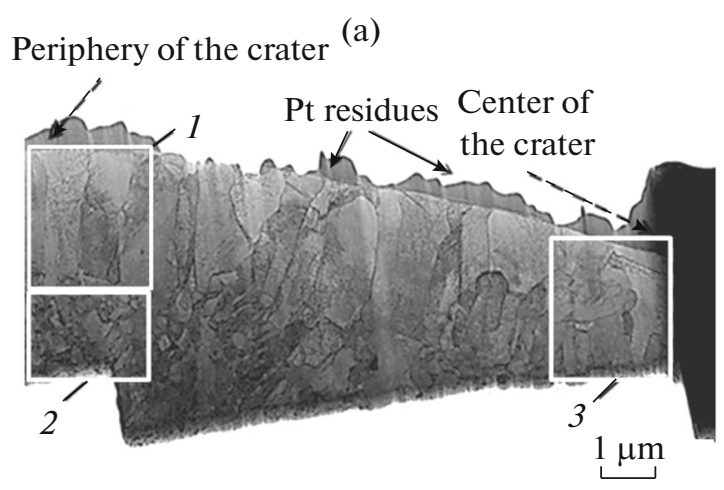

(b)

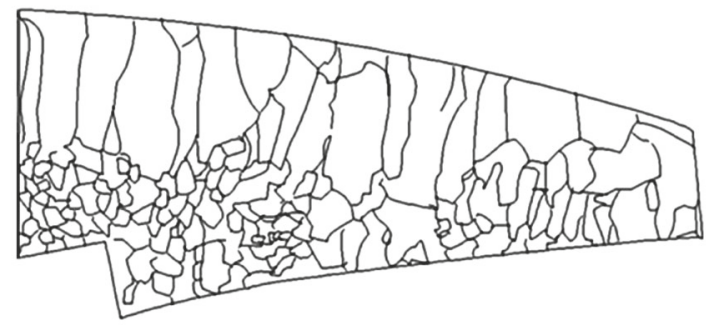

Fig. 2. Microstructure of cross section of the crater (a) and chart of it (b). ter consists of columnar grains extended in the direction of the surface with an average length of $\sim 2 \mu \mathrm{m}$ and the value of the grain nonuniformity coefficient (GNC) greater than 3 (Fig. 2, region 1, Fig. 3a). The value of GNC decreases with shifting from the peripheral ring of the crater to its central part (Fig. 2, region 3, Fig. 3c). Under the layer of elongated crystallites in the crater, there is a region with equiaxial submicrocrystalline (SMC) grains, whose average size is $250 \mathrm{~nm}$ (Fig. 2, region 2, Fig. 3b).

The character of the formed structure definitely indicates the progress of melting and superfast crystallization in a thin near-surface layer in the process of crater formation. The formation of SMC grains with a fairly high density of dislocations under a layer of columnar crystals can also be indicative of the shockwave mechanism of the action of HPPIB on the nearsurface layer of the metal being processed.

Currently, there are various assumptions about the nature and mechanisms of the formation of cratersinhomogeneity of the ion beam density in the pulse [2], the presence of gas impurities in the material and the escape of gas bubbles to the molten surface [3], the effect of the recoil momentum produced upon local melting and evaporation of the target [4], the formation 




(a) $200 \mathrm{~nm}$



(b)

$200 \mathrm{~nm}$

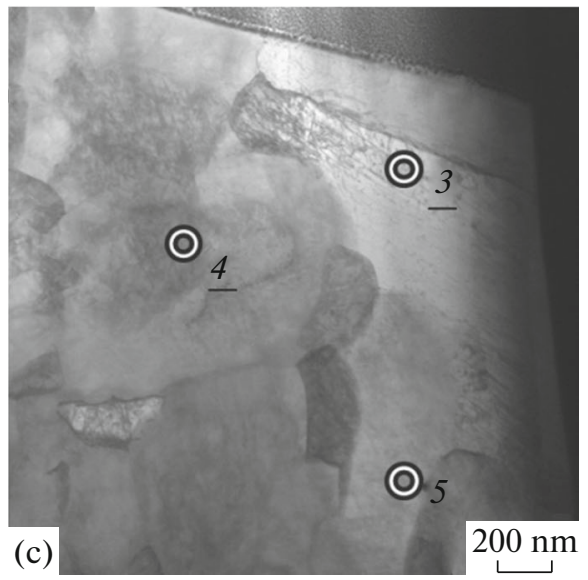

Fig. 3. Microstructure of different areas of the crater: (a) periphery (Fig. 2a, area 1); (b) periphery (Fig. 2a, area 2); (c) center (Fig. 2a, area 3). Digitized highlighters designate the areas for elemental microanalysis.

of a plasma torch followed by the appearance of instability of the plasma-melt boundary [5]. Within the framework of the model [5], it is also shown that, in the process of crater formation under its surface, stress fields arise that exceed the yield strength, which can be responsible for structural changes in the near-surface layer.

According to the EMF data (Table 1), in the central region the crater, redistribution of alloying elements
Table 1. Elemental composition of different areas of the crater, wt \%. Areas analyzed are emphasized by highlighters in Fig. 3

\begin{tabular}{c|c|c|c}
\hline Area of analysis & $\mathrm{Ni}$ & $\mathrm{Cr}$ & $\mathrm{Fe}$ \\
\hline 1 & 9.3 & 14.6 & 73.2 \\
2 & 7 & 15.7 & 75.9 \\
3 & 19.5 & 2.7 & 76.3 \\
4 & 15.5 & 4.3 & 78.8 \\
5 & 9.5 & 4.8 & 84.2 \\
\hline
\end{tabular}

occurs with the emergence of areas with a high content of nickel and low content of chromium. In the process of crater formation, significant vaporization of chromium is also possible owing to high elasticity of its vapor.

\section{CONCLUSIONS}

During HPPIB irradiation of 12Cr18Ni10Ti steel $\left(3 \mathrm{~J} / \mathrm{cm}^{2}, 10\right.$ pulses), craters with density of at least $10^{4} \mathrm{~cm}^{-2}$ are formed on its surface. Electron microscopic studies of the cross section of the crater have shown that a zone of columnar grains stretched toward the surface is formed in the near-surface crater layer with a depth of $\sim 2 \mu \mathrm{m}$, and a region with equiaxial SMC grains is formed under it.

\section{ACKNOWLEDGMENTS}

The work on the crater study by the TEM method was supported by the State Task of the Ministry of Education to Higher Education Institutions no. 3.3144.2017/ПЧ. The work on surface processing of the samples at the TEMP installation was supported by the Russian Foundation for Basic Research, grant no. 14-08-00632.

\section{REFERENCES}

1. Isakov, I.F., Kolodii, V.N., Opekunov, M.S., Matvienko, V.M., Pechenkin, S.A., Remnev, G.E., and Usov, Yu.P., Sources of high power ion beams for technological applications, Vacuum, 1991, vol. 42, nos. 1-2, pp. 159-162.

2. Pogrebnyak, A.D. and Kul'ment'eva, O.P., Structurephase transformations in near-surface layers and properties of metal materials after pulse treatment by particle beams, Fiz. Inzh. Poverkhn., 2003, vol. 1, no. 2, pp. 110-136.

3. Chernov, I.P., Beloglazova, P.A., Berezneeva, E.V., Kireeva, I.V., Pushilina, N.S., Remnyov, G.E., and Stepanova, E.N., Properties of the VT1-0 titanium surface modified by a pulsed ion beam, Tech. Phys., 2015, vol. 60 , no. 7 , pp. 1039-1043.

4. Korotaev, A.D., Tyumentsev, A.N., Pinzhin, Yu.P., and Remnev, G.E., Features of the morphology, defect substructure, and phase composition of metal and alloy surfaces upon high-power ion beam irradiation, Surf. Coat. Technol., 2004, vol. 185, pp. 38-49.

5. Volkov, N.B., Maier, A.E., and Yalovets, A.P., On the mechanism of cratering on solid surfaces exposed to an intense charged particle beam, Tech. Phys., 2002, vol. 47 , no. 8 , pp. 968-977.

Translated by Sh. Galyaltdinov 